\title{
BMJ Open The determinants and outcomes of good provider communication: a cross- sectional study in seven African countries
}

\author{
Elysia Larson, Hannah H Leslie, Margaret E Kruk
}

To cite: Larson E, Leslie HH, Kruk ME. The determinants and outcomes of good provider communication: a crosssectional study in seven African countries. BMJ Open 2017;7:e014888. doi:10.1136/ bmjopen-2016-014888

- Prepublication history and additional material are available. To view these files please visit the journal online (http://dx.doi org/10.1136/bmjopen-2016014888).

Received 26 0ctober 2016 Revised 25 April 2017 Accepted 18 May 2017

CrossMark

Department of Global Health and Population, Harvard T.H. Chan School of Public Health, Boston, Massachusetts, USA

Correspondence to

Ms Elysia Larson; ell539@mail. harvard.edu

\section{ABSTRACT}

Objectives To determine the extent of provider communication, predictors of good communication and the association between provider communication and patient outcomes, such as patient satisfaction, in seven subSaharan African countries.

Design Cross-sectional, multicountry study. Setting Data from recent Service Provision Assessment (SPA) surveys from seven countries in sub-Saharan Africa. SPA surveys include assessment of facility inputs and processes as well as interviews with caretakers of sick children. These data included 3898 facilities and 4627 providers.

Participants 16352 caregivers visiting the facility for their sick children.

Primary and secondary outcome measures We developed an index of four recommended provider communication items for a sick child assessment based on WHO guidelines. We assessed potential predictors of provider communication and considered whether better provider communication was associated with intent to return to the facility for care.

Results The average score of the composite indicator of provider communication was low, at 35\% (SD 26.9). Fiftyfour per cent of caregivers reported that they were told the child's diagnosis, and only $10 \%$ reported that they were counselled on feeding for the child. Caregivers' educational attainment and provider preservice education and training in integrated management of childhood illness were associated with better communication. Private facilities and facilities with better infrastructure received higher communication scores. Caretakers reporting better communication were significantly more likely to state intent to return to the facility (relative risk: $1.19,95 \% \mathrm{Cl} 1.16$ to 1.22 ).

Conclusions There are major deficiencies in communication during sick child visits. These are associated with lower provider education as well as less well-equipped facilities. Poor communication, in turn, is linked to lower satisfaction and intention to return to facility among caregivers of sick children. Countries should test strategies for enhancing quality of communication in their efforts to improve health outcomes and patient experience.

\section{INTRODUCTION}

Healthcare utilisation has increased in many low-income and middle-income countries

\section{Strengths and limitations of this study}

- This study combines data from health facility surveys with reports from patients on their experience. This unique combination allows us to assess the association between communication and characteristics of health facilities, providers and patient populations.

- In addition to empirically assessing extent and predictors of communication, this analysis is able to look at outcomes related to future behaviours, including satisfaction with the health system and intent to return to the facility for future care.

- This is a large, multicountry study that assesses communication across different levels of healthcare and in many settings. However, a limitation of this study is that it is cross-sectional and cannot determine causality in assessed relationships.

(LMICs) in the past decade as a result of national and international focus on improving access to services. ${ }^{1}$ However, such gains in utilisation are not always matched by improvements in health outcomes, which are still disproportionately poor in LMIC. ${ }^{2}$ This may be due to the low quality of healthcare patients receive once they reach the health system. ${ }^{34}$

Measures of the quality of healthcare are typically analysed in three domains: infrastructure, process and outcome. ${ }^{5}$ The process of care can be further divided into technical quality of clinical care and patient experience or interpersonal quality. ${ }^{6}$ Technical quality refers to the application of clinical medicine to a specific health problem, while patient experience measures focus on responsiveness of the health system to the patient's non-health needs. The WHO's 2000 World Health Report and subsequent theoretical work have defined the following eight domains of patient experience: dignity, autonomy, confidentiality, communication, choice of provider, timely attention, quality of basic amenities and social support. ${ }^{78}$ 
Provider communication is a particularly important component of patient experience. Strong communication between providers and patients may enable patients to disclose relevant information and to adhere to prescribed treatment. ${ }^{89}$ There is evidence in high-income countries that strong provider communication is associated with measures of technical quality. ${ }^{9}{ }^{10}$ In addition, better provider-patient communication is associated with better perceived and objectively measured patient health outcomes. ${ }^{11} 12$

Despite growing evidence of the influence of patientprovider communication on caregiver behaviours and health outcomes in high-income settings, the quality and impact of provider communication in LMIC is not as well documented. The different structure of the healthcare system and distinct social contexts warrant caution in assuming that the relationships found in one environment will be reflected in the other. ${ }^{13}$

Understanding the determinants and outcomes of patient communication is essential in LMIC, which bear a disproportionate burden of childhood morbidity and mortality and stand to gain the most from improvement in provider-patient communication if the link between communication and outcomes is found to be strong. ${ }^{2}{ }^{14}$ We therefore had two objectives for this analysis. First, we described provider communication and its predictors during visits for sick children in health facilities across seven sub-Saharan African countries. Second, we quantified the association between provider communication and key outcomes of a healthcare visit: caregivers' satisfaction with and impressions of the visit, caregivers' intent to return to the facility if the child does not improve completely and caregivers' recommendation of the facility to family and friends.

\section{METHODS}

\section{Data collection and survey design}

This analysis uses data from the Service Provision Assessment (SPA) surveys, which are conducted by the Demographic and Health Survey Programme. ${ }^{15}$ These health facility-based surveys have been completed over the past 10 years in seven countries in sub-Saharan Africa (Kenya (2010), Malawi (2013), Namibia (2009), Rwanda (2007), Senegal (2012-2014), Tanzania (2015) and Uganda (2007)). The SPA surveys include assessment of facility inputs and processes and health worker interviews as well as direct clinical observations and client exit interviews (sample sizes presented in online supplementary appendix 1). This analysis focuses on data from client exit interviews for visits for sick children. Additional covariates are drawn from the surveys of facility inputs and processes and health worker interviews.

SPA survey selection follows a two-stage design. Except in Rwanda, Namibia and Malawi, where a census of all or nearly all facilities was conducted, each country's health facilities were randomly sampled after stratifying by type of facility (eg, hospital or health centre) and managing authority. Hospitals tend to be oversampled in SPA surveys. Within each health facility, patients were selected using systematic sampling. The anticipated number of patients to be seen on the day of data collection was divided by 15 to determine the interval length needed to sample 15 patients from the facility. ${ }^{15}$ Survey weights are assigned to each child to account for both the facility and patient stages of sampling such that the weighted sample should be representative of the population of all clients seeking care. We scaled weights within each country to maintain the sample size. ${ }^{15}$ Health workers observed providing care were interviewed about their education and training; sampling weights were similarly calculated to ensure a representative sample of healthcare providers.

Informed consent was collected from the facility in-charge as well as each individual respondent before continuing with the interview. ${ }^{16}$

\section{Measurement of provider communication}

We used the 2014 WHO guidelines for the integrated management of childhood illness (IMCI) ${ }^{17}$ to identify essential elements of provider communication during sick child visits. The primary requirements of provider communication in the IMCI guidelines are clear statement of the child's diagnosis and of the recommended treatment and follow-up plan. To capture these elements, we defined four indicators of quality communication: provider told the caregiver the child's illness, told the caregiver the symptoms that would indicate a need for immediate return to the facility, scheduled or discussed a return visit, and counselled the caretaker on feeding the child (the caregiver responded that the provider counselled them on either feeding solid foods or giving fluids during this illness). These indicators were assessed using the caretakers' recall of this communication following the clinical consultation. We excluded three indicators that addressed communication of medication for the child, as these indicators may in some cases be endogenous with provision of good technical quality (provision of an appropriate treatment plan). We calculated communication quality as the proportion of the four items performed for each visit.

\section{Covariates}

To identify determinants of good communication, we selected predictors identified using recent literature and shown on our conceptual framework (figure 1). ${ }^{18-20}$ At the patient level, these included both the caregiver and child's sociodemographic characteristics as well as whether the caregiver paid for the visit and whether the caregiver was part of a prepayment plan, such as insurance. In order to capture potentially different treatment by the child's presenting illness, we assessed the reasons for the child's visit as stated by the caregiver (fever, cough, diarrhoea, vomiting, feeding problems, sleeping problems and convulsions). At the provider level, we assessed providers' education (both number of years of preservice education and whether they had 


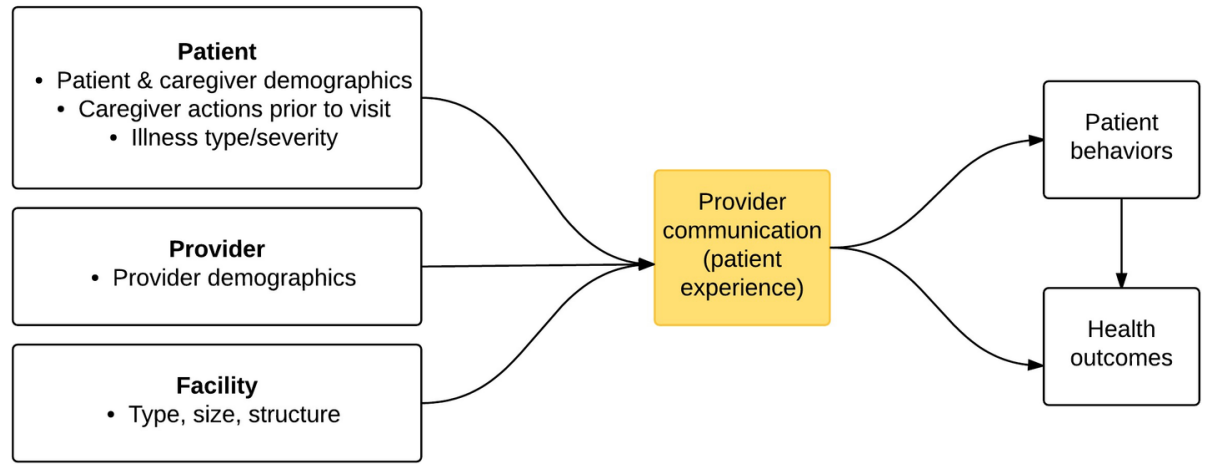

Figure 1 Conceptual framework of the relationship between patient-level, provider-level and facility-level characteristics with communication, patient behaviours and outcomes.

received recent, in the past 1-2 years, IMCI-related training), providers' cadre (doctor or clinical officer versus nurse versus other), how long they have worked as a clinician, and whether the provider is a manager. At the facility level, we looked at whether the facility had received recent supportive supervision, the level of infrastructure available (an index of 22 items including water and electricity), the level of management support (an index of 7 items including whether quality assurance activities are routinely carried out), whether the facility was public or private, and the level of the facility (comparing hospitals with non-hospitals).

We assessed the relation between communication and outcomes related to the caregivers' experience: caregiver satisfaction, caregivers' intent to return to the facility, caregivers' recommendation of the facility, and caregivers' perception of whether there were problems with the care provided. Caregivers were asked to rate their satisfaction with the services received on a three-level scale (very satisfied, more or less satisfied or not satisfied). We dichotomised the variable as 'very satisfied' versus 'not very satisfied'. Caregivers were also asked what they would do if the child did not get completely better or became worse. We coded caregivers' responses as either 'return to this facility' or 'not return', where not returning could include going to another facility, another health worker, a traditional healer or just waiting (eg, do not see a healthcare provider.) Caregivers were also asked whether they would recommend this facility to a friend of family member. Finally, caregivers were asked whether certain aspects of care were major, minor or no problem for them. We dichotomised these responses into either 'problem' or 'no problem'.

\section{Data analysis}

We first explored the level and potential predictors of provider communication in the seven countries. We calculated descriptive statistics of the population-averaged indicators of interest using data weighted to represent the health system in each country. We screened each potential indicator in a linear regression of provider communication, controlling for country and clustering at the provider level. We retained all covariates significant at $\mathrm{p} \leq 0.05$, removing those that were highly correlated with other retained predictors.

We then assessed the predictors of communication using generalised hierarchical linear regression models. Hierarchical models were selected because they enable assessment of the association of both patient-level and provider-level or facility-level characteristics with the communication index as well as calculation of the variation in the outcome attributable to the client versus provider. The first model included only country fixed effects, the second model added individual-level elements and the third model included individual-level, provider-level and facility-level elements with country fixed effects. We used the MIXED command with the MLE option in Stata 14.1 for all models. We included a random intercept for provider and calculated the intraclass correlation coefficient (ICC). The ICC is interpreted as the proportion of the total variation in the outcome that is due to provider-level variation.

While the SPA surveys aim to collect data from multiple patient visits for each provider, this is not always the case. Over the seven countries surveyed, there were 559 providers $(4 \%)$ where only one child visit was observed. For these providers, the contribution at the child level cannot be calculated; we corrected for this by preventing the stratum from contributing to the variance at the child level.

The second part of our analysis assessed the association between provider communication and patient outcomes using generalised estimating equations. We calculated risk ratios using a log link, exchangeable correlation structure and robust sandwich estimator to account for clustering at the provider level. A fixed effect for country was included in the unadjusted models. Adjusted models controlled for potential confounders at the patient level, provider level and facility level; these covariates were selected because of their theorised association with both provider communication and the outcomes of interest.

All analyses were conducted using Stata 14.1. The institutional review board at the Harvard T.H. Chan School of Public Health determined this analysis to be exempt from human subjects review. 
Table 1 Client, provider and facility characteristics for outpatient visits for sick children in seven sub-Saharan African countries

\begin{tabular}{lll}
\hline & $\begin{array}{l}\text { Weighted } \mathbf{n} \\
\text { or mean }\end{array}$ & \% or SD \\
\hline Total visits & 16352 & \\
\hline Total providers & 4627 & \\
\hline Total facilities & 3898 & \\
Visit level & & \\
\hline Caregiver's age (years) & 28.1 & 8.2 \\
\hline Caregiver is female & 13744 & $91.2 \%$ \\
\hline Caregiver's education & & \\
\hline \multicolumn{1}{l}{ None } & 3705 & $22.7 \%$ \\
\hline Any primary & 8701 & $53.3 \%$ \\
\hline Any secondary & 3430 & $21.0 \%$ \\
\hline Any tertiary or higher & 493 & $3.0 \%$ \\
\hline Caregiver is child's parent & 14446 & $89.0 \%$ \\
\hline Child's age (months) & 20.3 & 15.2 \\
\hline Child is female & 7904 & $48.5 \%$ \\
\hline Client paid for visit & 6769 & $41.4 \%$ \\
\hline Client has insurance* & 3102 & $19.1 \%$ \\
\hline Duration of visit (min) & 12.9 & 15.8 \\
\hline Reasons caregiver brought child & \\
\hline
\end{tabular}

Reasons caregiver brought child to the facility $\dagger$

\begin{tabular}{|lll|}
\hline Fever & 11894 & $73.5 \%$ \\
\hline Cough & 11102 & $68.1 \%$ \\
\hline Diarrhoea & 4898 & $30.2 \%$ \\
\hline Problems feeding & 4083 & $25.2 \%$ \\
\hline Excessive sleepiness & 3724 & $23.0 \%$ \\
\hline Convulsions & 3516 & $21.7 \%$ \\
\hline
\end{tabular}

Provider level

\begin{tabular}{|lll}
\hline Provider is female & 7552 & $46.2 \%$ \\
\hline $\begin{array}{l}\text { Provider's years of education } \\
\text { Provider's years since graduation }\end{array}$ & 15.0 & 2.9 \\
\hline $\begin{array}{l}\text { Provider years in this facility } \\
\text { Provider's cadre }\end{array}$ & 4.7 & 10.0 \\
$\quad$ Doctor or clinical officer & 7480 & 6.4 \\
$\quad$ Nurse & 6633 & $45.8 \%$ \\
\hline $\begin{array}{l}\text { Non-clinical staff } \\
\text { Provider is a manager }\end{array}$ & 2224 & $13.6 \%$ \\
\hline $\begin{array}{l}\text { Received recent training on sick } \\
\text { child care }\end{array}$ & 9987 & $61.5 \%$ \\
\hline $\begin{array}{l}\text { Number of in-service training } \\
\text { topics covered in past 3 years }\end{array}$ & 6332 & 3.0 \\
\hline $\begin{array}{l}\text { Facility level } \\
\text { Private facility }\end{array}$ & $38.9 \%$ \\
\hline Hospital & 3461 & $21.2 \%$ \\
\hline & 2620 & $16.0 \%$ \\
\hline
\end{tabular}

Table 1 Continued

\begin{tabular}{lll|}
\hline & \multicolumn{2}{l}{ Weighted $\mathbf{n}$} \\
& or mean & \% or SD \\
\hline $\begin{array}{lll}\text { Received supportive supervision } \\
\text { in last 6 months }\end{array}$ & 12378 & $76.2 \%$ \\
\hline Infrastructure index $\ddagger$ & 0.55 & 0.17 \\
\hline
\end{tabular}

Data from Rwanda and Namibia are self-weighted, and in Malawi, a non-response weight is used. Data from Kenya, Senegal, Tanzania and Uganda are weighted to reflect sampling probability. For some rows, denominators differ from the total ' $n$ ' owing to missing data.

${ }^{*}$ Client has medical aid, insurance or other prepayment plan. †Caregivers could report multiple reasons for bringing the child to the facility for services.

¥Mean proportion of 22 items including water, ambulance, electricity, phone, toilet, cleanliness, wait room, system for maintenance, sharps disposal, waste disposal, sterilised equipment storage, consumables storage, no expired medications, medication storage, medication supply, stock ledger, pourable water, soap, gloves, sharps box, surface disinfectant and hand disinfectant.

\section{Sensitivity analyses}

We conducted multiple sensitivity analyses to assess the robustness of the results to the methods used for missing data and model specification. To ensure results were not affected by missing data, we conducted multiple imputation and repeated the analysis on 20 imputed datasets (see online supplementary appendix 2 ). We also removed providers with a single clinical observation to better assess variation within versus between providers. Finally, we repeated the model using sampling weights accounting for the provider's probability of inclusion in the sample. Results for these final two models are presented in online supplementary appendix 3 .

\section{RESULTS}

A total of 16352 outpatient visits for sick children from 3898 facilities and 4627 providers were included in this analysis (table 1 and online supplementary appendix 1 table 1 ). On average, children were 20 months ( 1.7 years) old at the time of their visit. Fever was the most common reason caretakers cited for the visit $(74 \%)$. Forty-one per cent of the healthcare providers were nurses, and $16 \%$ of the visits included were at hospitals (table 1 ).

The average score on the composite indicator of provider communication was low, at $35 \%$, with a SD of 26.9 percentage points. In $23 \%$ of visits, the caregiver reported that the provider did not complete any of the communication tasks, whereas $3 \%$ of caregivers reported the provider completed all communication tasks. Fifty-four per cent of caregivers reported that they were told the child's diagnosis, and only $10 \%$ reported that they were counselled on feeding or providing liquids for the child (figure 2).

While most of the variables included in the full model assessing factors contributing to provider communication had a statistically significant association with patient experience, the effect size was generally small (table 2 ). 
On average, caregivers who had achieved tertiary education experienced provider communication that rated 4.9 percentage points better than those with no education. On the provider side, providers who had received training in selected child health topics in the past 1-2 years, providers who were managers, female providers and nurses all scored higher on the communication scale. These associations were all modest, with training having the largest association with an increase of 4.4 percentage points on the communication scale. Observations in private facilities and those that had received a supportive supervision visit were also associated with better communication scores. The patient-level and provider-level characteristics included in the model were able to account for minimal variation between providers. Most of the variation in the communication index was due to unexplained patientlevel variation and random error, with $35 \%$ of variation in the full model due to provider-level effects.

The provider communication index was significantly associated with all assessed outcomes (table 3). Patients who reported a perfect score on provider communication were 1.21 times as likely to be very satisfied with their visit than patients whose provider scored 0 on the communication index (95\% CI 1.17 to 1.26 ). There was also a strong association between provider communication and a patient's stated intent to return if the child did not get completely better: risk ratio 1.19 (95\% CI 1.16 to 1.22). Adjusting for potential confounders did not change the measures of effect. The results were robust to the performed sensitivity checks (see online supplementary appendix).

\section{DISCUSSION}

Across more than 16000 visits for sick children in seven sub-Saharan African countries, provider communication was poor. These findings from nationally representative surveys of facilities corroborate findings of inadequate provider-patient communication, low quality of technical care and poor provider effort from smaller studies in LMIC. ${ }^{21-23}$ Additionally, there is evidence that higher communication is associated with both higher client satisfaction and intent to return to care.

Although the average provider communication score was low in each of the countries studied at the time of data collection, it varied from 26\% in Senegal (2012-2014) to a high of $49 \%$ in Uganda (2007). All seven countries are low- or lower middle-income countries and all are experiencing shortages of skilled health providers. ${ }^{24}$ Between-country variation on the communication index did not follow trends in gross domestic product per capita, economic inequality, health spending or availability of skilled health providers. ${ }^{24}{ }^{25}$ There was some evidence of a decline in communication score by the year that the survey was conducted, which ranged from 2007 to 2015, but this cannot be distinguished from between-country contextual differences.

We found a number of client-level and provider-level factors with modest, but statistically significant associations with patients' report of provider communication. The level of reported provider communication increased with caregiver's education. Visits with caregivers who had some secondary school were rated four percentage points higher on communication than visits with caregivers who had no formal education. There are several possible reasons for this association. Educated caregivers may be more likely to initiate communication with providers or may have a higher capacity to understand providers and remember what has been communicated. Alternatively, providers may make a choice about what to communicate based on the education level of caregivers. Regardless of the aetiology for the disparity, it is important for providers to recognise it and focus on improving communication with individuals with lower education using methods

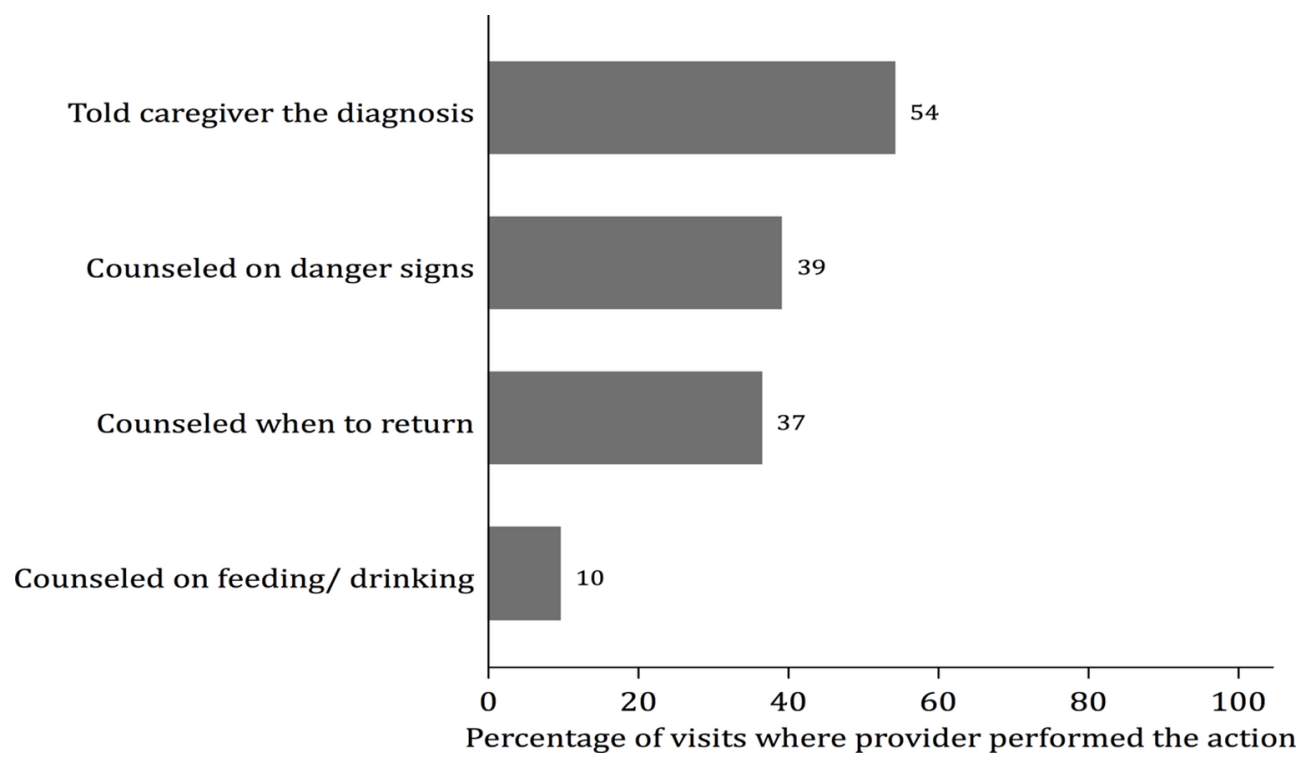

Figure 2 Frequency of provider communication across seven sub-Saharan African countries, data from patient report; $\mathrm{n}=16352$. For each indicator, values were missing from $0.2 \%$ to $0.6 \%$ of exit interviews. 
Table 2 Results of the multilevel linear regression of provider communication during sick child visits in seven sub-Saharan African countries

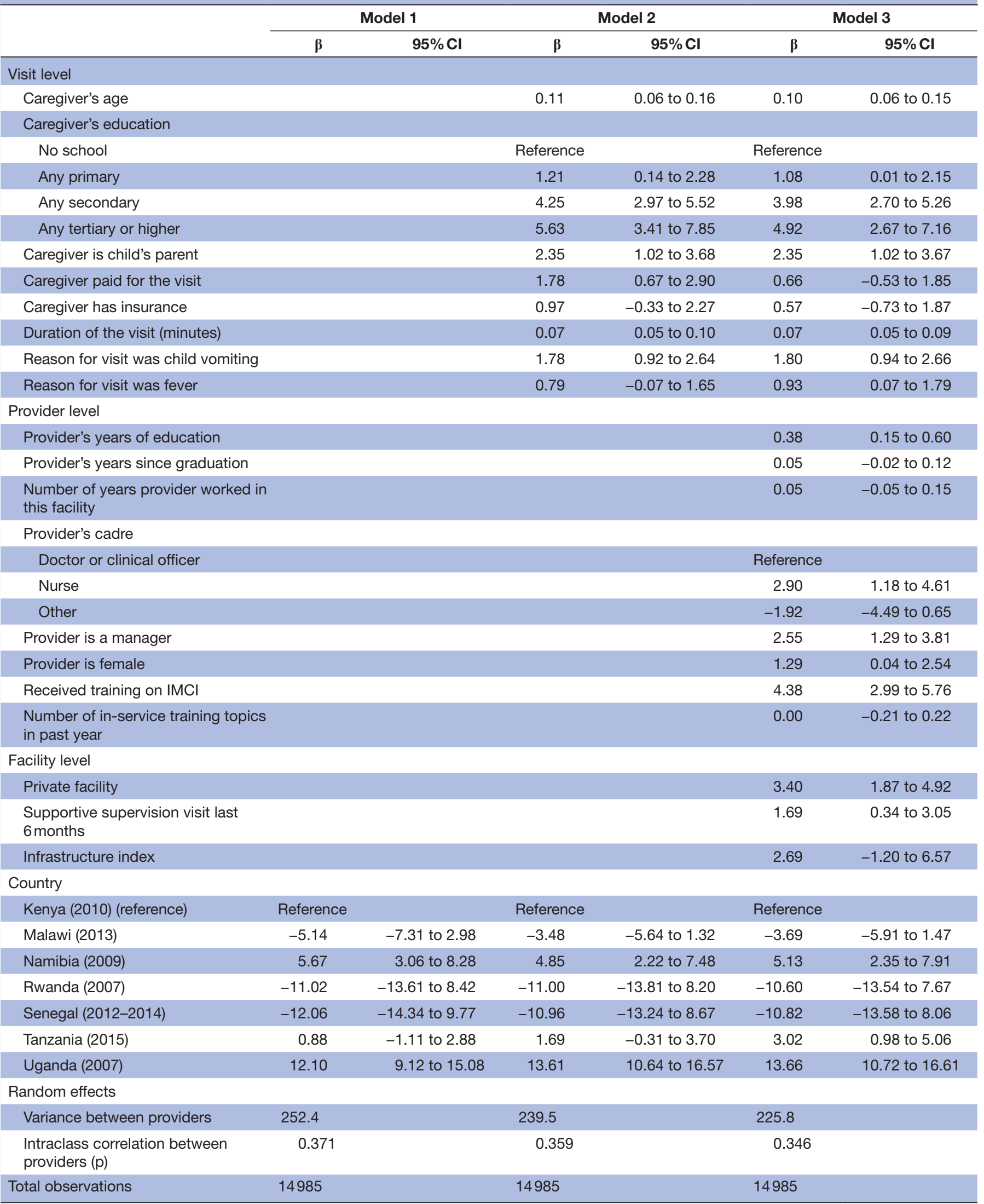

${ }^{*}$ The outcome, provider communication, is on a scale from $0 \%$ to $100 \%$ and is measured during exit interviews with the caregiver. $\mathrm{IMCl}$, integrated management of childhood illness. 


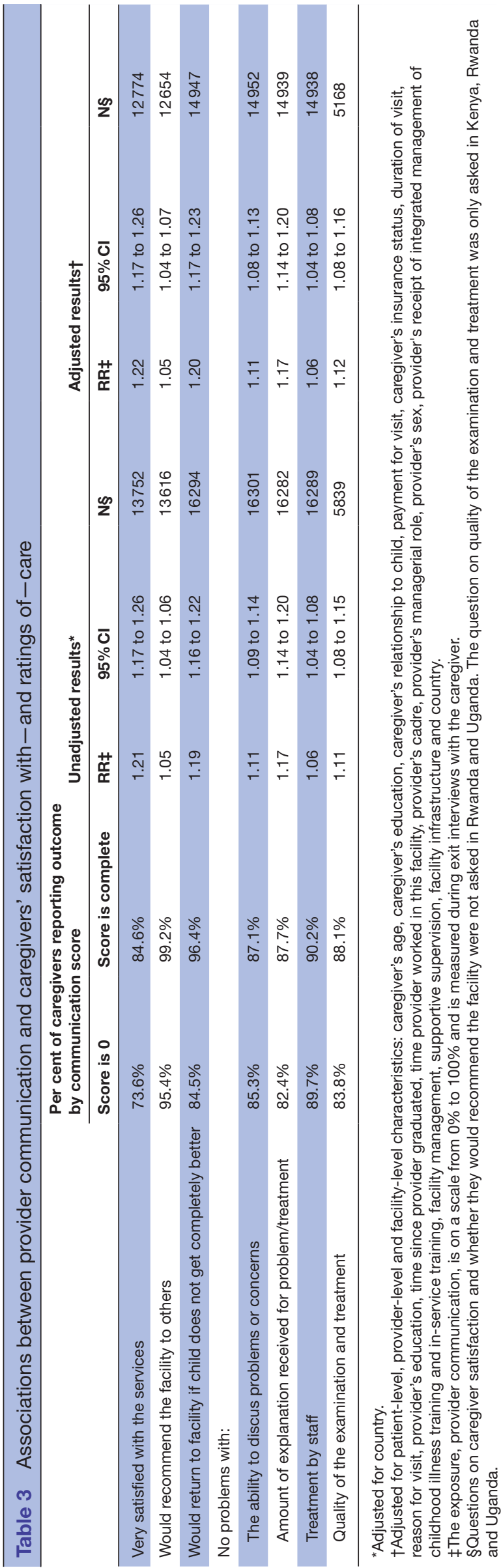

that improve patient understanding. While there are many examples of successful interventions for improving patient-provider communication in high-income countries, there are few in LMIC. ${ }^{26}$ Job aids may be one way to aid in provider communication and patient understanding, particularly among patients and caregivers with low educational attainment. ${ }^{23}$

Providers with fewer years of training, such as counsellors and community health workers, were less likely to provide high-quality communication. These findings highlight the importance of assessing provider communication, as well as technical care and health outcomes, when evaluating the impact of task-shifting responsibilities from doctors and nurses to staff with less training. Visits with nurses were associated with better communication than both clinical officers and non-clinically trained providers. Training on sick child care was associated with slightly better communication, which supports results from a more detailed, but smaller study on the impact of IMCI training on the quality of counselling provided in sick child visits in Mali. ${ }^{27}$ However, the increase in communication found here was small: only four percentage points. A systematic review of randomised controlled trials of communication interventions for healthcare providers, primarily within the USA, found that communication interventions can have a positive effect on provider-patient communication, with the effect stronger for more intensive interventions. ${ }^{28}$ Successful trainings in US programs included demonstration of communication skills, observation, constructive feedback and opportunities for clinicians to review their own responses. ${ }^{26}{ }^{28}$ While two reviews of IMCI training in LMIC found that both recent training and the length of training had little effect on the provision of technical quality indicators, ${ }^{29} 30$ there is some evidence that training interventions focused on patient-centred communication may have positive effects on communication in SSA. ${ }^{31-33}$ Our results combined with those from communication interventions suggest the potential for using training to improve provider-patient communication.

Most of the variation in communication was due to differences between patients and visits, rather than differences between providers, which reflect similar findings from a study on provider communication in the UK. ${ }^{34}$ Two studies from SSA that looked at technical quality indicators found that quality variation was largely due to provider-level and facility-level differences. ${ }^{35} 36$ These discordant findings may indicate that provider-level and facility-level factors may be a stronger barrier to highquality technical care than to communication. Reasons why many providers were able to communicate well for some visits and not for others should be explored further so that context-specific support or training can be given to providers.

We found that higher provider communication was related to patients' satisfaction and intent to return. While the association of strong patient-provider communication with an increase in patient adherence to prescribed 
treatments and recommended prevention processes has been extensively documented, ${ }^{37-39}$ this is the first evidence we are aware of from a multicountry study in sub-Saharan Africa documenting the association between strong provider communication and patient satisfaction and planned behaviours.

This study has several limitations. First, these surveys took place between 2007 and 2015; between-country differences may reflect both contextual differences as well as changes over time. Second, these data were collected during visits when providers knew that they were being observed. It is possible that the Hawthorne effect could have affected healthcare provider behaviour, particularly because there were fewer than five patient observations for each healthcare provider. ${ }^{40}$ However, if healthcare providers were indeed performing to the best of their capabilities during these observed visits, then it is even more concerning that the levels of quality observed were so low, as these results would represent the upper bound of care quality. Third, in many of the regions studied, multiple languages are spoken, and in some cases, the provider and caregiver may not share a common language. While language congruency is not measured in the SPA, we do not anticipate this to be an issue in the majority of clinics. Fourth, the indicators on the communication index are measured from the patient perspective, and we cannot determine if the items were not communicated by the provider or if they were communicated and not heard or understood by the patient. Understanding this difference may provide insight into which interventions would be most effective. However, from a measurement perspective, the literature defines patient experience as patient defined, and thus patient experience measures, including communication, are most accurately measured from the patient perspective. ${ }^{41}$ Finally, the associations identified in this analysis cannot be interpreted causally.

Our findings are the first cross-country, nationally representative assessment of the predictors and outcomes of provider communication during visits for sick children. While there was variability between the countries in the level of provider communication, the general trends were consistent: provider communication was low, and improved provider communication was associated with higher patient satisfaction and higher intention to return to the same facility. It is possible that these results are generalisable to similar countries in the region.

The results highlight the importance of testing strategies that enhance clinical communication as a means for improving outcomes and patient experience in LMIC. Because communication gaps appeared to be higher for caregivers with lower education, these strategies could focus on targeting this population. Additional entry points for strategies for improving clinical communication may be in focusing on staff without strong clinical training and those in public facilities.
Contributors EL and MEK developed the study question. EL conducted all analyses and drafted the manuscript. All authors contributed to the analysis plan, revised the manuscript and approved the final version for publication.

Competing interests None declared.

Provenance and peer review Not commissioned; externally peer reviewed.

Data sharing statement All data used in this analysis are publically available from the Demographic and Health Survey Program (http://dhsprogram.com/data/ index.cfm\#CP_JUMP_13446). Statistical code can be obtained from the authors on request.

Open Access This is an Open Access article distributed in accordance with the Creative Commons Attribution Non Commercial (CC BY-NC 4.0) license, which permits others to distribute, remix, adapt, build upon this work non-commercially, and license their derivative works on different terms, provided the original work is properly cited and the use is non-commercial. See: http://creativecommons.org/ licenses/by-nc/4.0/

(C) Article author(s) (or their employer(s) unless otherwise stated in the text of the article) 2017. All rights reserved. No commercial use is permitted unless otherwise expressly granted.

\section{REFERENCES}

1. Scott KW, Jha AK. Putting quality on the global health agenda. $N$ Engl J Med 2014;371:3-5.

2. Wang $\mathrm{H}$, Liddell $\mathrm{CA}$, Coates $\mathrm{MM}$, et al. Global, regional, and national levels of neonatal, infant, and under-5 mortality during 1990-2013: a systematic analysis for the Global Burden of Disease Study 2013. Lancet 2014;384:957-79.

3. Kruk ME, Larson E, Twum-Danso NA. Time for a quality revolution in global health. Lancet Glob Health 2016;4:e594-e596.

4. Sobel HL, Huntington D, Temmerman M. Quality at the centre of universal health coverage. Health Policy Plan 2016;31:547-9.

5. Donabedian A. The quality of care. how can it be assessed? JAMA 1988;260:1743-8.

6. Campbell SM, Roland MO, Buetow SA. Defining quality of care. Soc Sci Med 2000;51:1611-25.

7. Valentine N, Darby C, Bonsel GJ. Which aspects of non-clinical quality of care are most important? Results from WHO's general population surveys of "health systems responsiveness" in 41 countries. Soc Sci Med 2008;66:1939-50.

77 World Health Organization. The world health report 2000 : health systems : improvingperformance. Geneva: World Health Organization,, 2000.

9. Doyle C, Lennox L, Bell D. A systematic review of evidence on the links between patient experience and clinical safety and effectiveness. BMJ Open 2013;3:e001570.

10. Anhang Price R, Elliott MN, Zaslavsky AM, et al. Examining the role of patient experience surveys in measuring health care quality. Med Care Res Rev 2014;71:522-54.

11. Kelley JM, Kraft-Todd G, Schapira L, et al. The influence of the patient-clinician relationship on healthcare outcomes: a systematic review and meta-analysis of randomized controlled trials. PLOS One 2014;9:e94207.

12. Stewart MA. Effective physician-patient communication and health outcomes: a review. CMAJ 1995;152:1423-33.

13. Blaise P, Kegels $G$. A realistic approach to the evaluation of the quality management movement in health care systems: a comparison between European and African contexts based on Mintzberg's organizational models. Int J Health Plann Manage 2004;19:337-64.

14. Organization WH. Children: reducing mortality. Secondary Children: reducing mortality. 2016. http://www.who.int/mediacentre/factsheets/ fs178/en/

15. Service Provision Assessment (SPA) Overview. Secondary Service Provision Assessment (SPA) Overview. http://dhsprogram.com/WhatWe-Do/Survey-Types/SPA.cfm.

16. Service Provision Assessment (SPA) Questionnaires. Secondary Service Provision Assessment (SPA) Questionnaires. http:// dhsprogram.com/What-We-Do/Survey-Types/SPA-Questionnaires. cfm.

17. WHO. Integrated management of childhood illness Chart Booklet. World Health Organization, 2014.

18. Rowe AK, de Savigny D, Lanata CF, et al. How can we achieve and maintain high-quality performance of health workers in low-resource settings? Lancet 2005;366:1026-35. 
19. McFarland DC, Shen MJ, Holcombe RF. Predictors of Satisfaction With Doctor and Nurse Communication: A National Study. Health Commun 2016:1-8.

20. Mead N, Bower P. Patient-centredness: a conceptual framework and review of the empirical literature. Soc Sci Med 2000;51:1087-110.

21. Das J, Hammer J. Quality of primary care in Low-Income Countries: facts and Economics. Annu Rev Econom 2014;6:525-53.

22. Das J, Gertler PJ. Variations in practice quality in five low-income countries: a conceptual overview. Health Aff 2007;26:w296-w309.

23. Jennings L, Yebadokpo AS, Affo J, et al. Antenatal counseling in maternal and newborn care: use of job aids to improve health worker performance and maternal understanding in Benin. BMC Pregnancy Childbirth 2010;10:75.

24. world health organisation. World Health Statistics 2016 data visualizations dashboard; SDG target 3.c. Health workforce. http:// apps.who.int/gho/data/node.sdg.3-c

25. World Development Indicators. The World Bank, 2014

26. Levinson W, Lesser CS, Epstein RM. Developing physician communication skills for patient-centered care. Health Aff 2010;29:1310-8.

27. Gilroy K, Winch PJ, Diawara A, et al. Impact of IMCI training and language used by provider on quality of counseling provided to parents of sick children in Bougouni District, Mali. Patient Educ Couns 2004;54:35-44.

28. Rao JK, Anderson LA, Inui TS, et al. Communication interventions make a difference in conversations between physicians and patients: a systematic review of the evidence. Med Care 2007;45:340-9.

29. Huicho L, Scherpbier RW, Nkowane AM, et al. How much does quality of child care vary between health workers with differing durations of training? An observational multicountry study. Lancet 2008;372:910-6.

30. Leslie HH, Gage A, Nsona H, et al. Training And Supervision Did Not Meaningfully Improve Quality Of Care For Pregnant Women Or Sick Children In Sub-Saharan Africa. Health Aff 2016;35:1716-24.
31. Nayiga S, DiLiberto D, Taaka L, et al. Strengthening patientcentred communication in rural Ugandan health centres: A theorydriven evaluation within a cluster randomized trial. Evaluation 2014;20:471-91.

32. Erb S, Letang E, Glass TR, et al. Health care provider communication training in rural Tanzania empowers HIV-infected patients on antiretroviral therapy to discuss adherence problems. HIV Med 2017.

33. Raymond M, Harrison MC. The structured communication tool SBAR (Situation, Background, Assessment and Recommendation) improves communication in neonatology. S Afr Med J 2014;104:850-2.

34. Salisbury C, Wallace M, Montgomery AA. Patients' experience and satisfaction in primary care: secondary analysis using multilevel modelling. BMJ 2010;341:c5004-c04.

35. Gathara D, English $M$, van Hensbroek MB, et al. Exploring sources of variability in adherence to guidelines across hospitals in low-income settings: a multi-level analysis of a cross-sectional survey of 22 hospitals. Implement Sci 2015;10:60.

36. Kruk ME, Chukwuma A, Mbaruku G, et al. Variation in quality of primary-care services in Kenya, Malawi, Namibia, Rwanda, Senegal, Uganda and the United Republic of Tanzania. Bull World Health Organ 2017;95:408-18.

37. Bartlett EE, Grayson M, Barker R, et al. The effects of physician communications skills on patient satisfaction; recall, and adherence. J Chronic Dis 1984;37:755-64.

38. Greenfield S, Kaplan SH, Ware JE, et al. Patients' participation in medical care: effects on blood sugar control and quality of life in diabetes. J Gen Intern Med 1988;3:448-57.

39. Zolnierek KB, Dimatteo MR. Physician communication and patient adherence to treatment: a meta-analysis. Med Care 2009;47:826-34.

40. Leonard K, Masatu MC. Outpatient process quality evaluation and the Hawthorne Effect. Soc Sci Med 2006;63:2330-40.

41. Toomey SL, Zaslavsky AM, Elliott MN, et al. The Development of a Pediatric Inpatient Experience of Care Measure: Child HCAHPS. Pediatrics 2015;136:360-9. 